\title{
Oxygen saturation targeting and changes in cerebral blood volume during postnatal stabilization in the delivery room
}

\author{
Bernhard Schwaberger $^{1}$; Corinna Binder-Heschl ${ }^{1}$, Gerhard Pichler ${ }^{1}$, Alexander Avian², \\ Nariae Baik-Schneditz ${ }^{1}$, Lukas Mileder ${ }^{1}$, Berndt Urlesberger ${ }^{1}$ \\ ${ }^{1}$ Research Unit for Cerebral Development and Oximetry, Division of Neonatology, Medical University of Graz, Graz, Austria \\ 2 Institute for Medical Informatics, Statistics and Documentation, Medical University of Graz, Graz, Austria
}

\section{BACKGROUND:}

Recently, our study group demonstrated that in healthy newborn infants cerebral blood volume (CBV) physiologically decreases immediately after birth. In infants receiving respiratory support the change of cerebral blood volume $(\triangle \mathrm{CBV})$ was significantly smaller, most probably due to less oxygen delivery to the brain.

OBJECTIVE: The aim of the present analysis was to investigate, whether preterm infants receiving respiratory support and showing $\mathrm{SpO}_{2}$ values below $80 \%$ at 5 minutes of age have differences in $\triangle \mathrm{CBV}$, compared to infants reaching the SpO target of $80 \%$ at 5 minutes.

\section{METHODS:}

Retrospective analysis of 5 prospective observational studies. Preterm infants receiving respiratory support during delivery room stabilization were included.

$\triangle \mathrm{CBV}$ was measured with near-infrared spectroscopy (NIRS) during the first 15 minutes after birth using the "NIRO 200-NX" device (Hamamatsu). According to $\mathrm{SpO}_{2}$, infants were divided into two groups: those with a 5 minute $\mathrm{SpO}_{2} \geq 80 \%$ ( $\geq 80 \%$ group) and those with a 5 minute $\mathrm{SpO}_{2}<80 \%$ ( $<80 \%$ group).

\begin{tabular}{|c|c|c|}
\hline & $\begin{array}{c}\text { "group } \geq 80 \% " \\
(n=25)\end{array}$ & $\begin{array}{c}\text { "group }<80 \% \text { " } \\
(n=27)\end{array}$ \\
\hline Gestational age, weeks & $32.0 \pm 1.8$ & $32.7 \pm 1.6$ \\
\hline Birth weight, gram & $1610 \pm 574$ & $1889 \pm 445$ \\
\hline APGAR $1^{\wedge}$ & $8(4-9)$ & $8(5-9)$ \\
\hline APGAR $5^{\wedge}$ & $9(8-10)$ * & $8(7-9)$ \\
\hline APGAR $10^{\wedge}$ & $9(8-10)$ & $9(8-10)$ \\
\hline pH umbilical artery & $7.30 \pm 0.04$ & $7.31 \pm 0.05$ \\
\hline Male sex $\%$ & $13(52)$ & $12(44)$ \\
\hline
\end{tabular}

Tab. 1: Patient Demographic Characteristics. * $p=0.05$

Data are presented as mean $\pm \mathrm{SD}$, unless indicated $\% \mathrm{n}(\%),{ }^{\wedge}$ median (range)

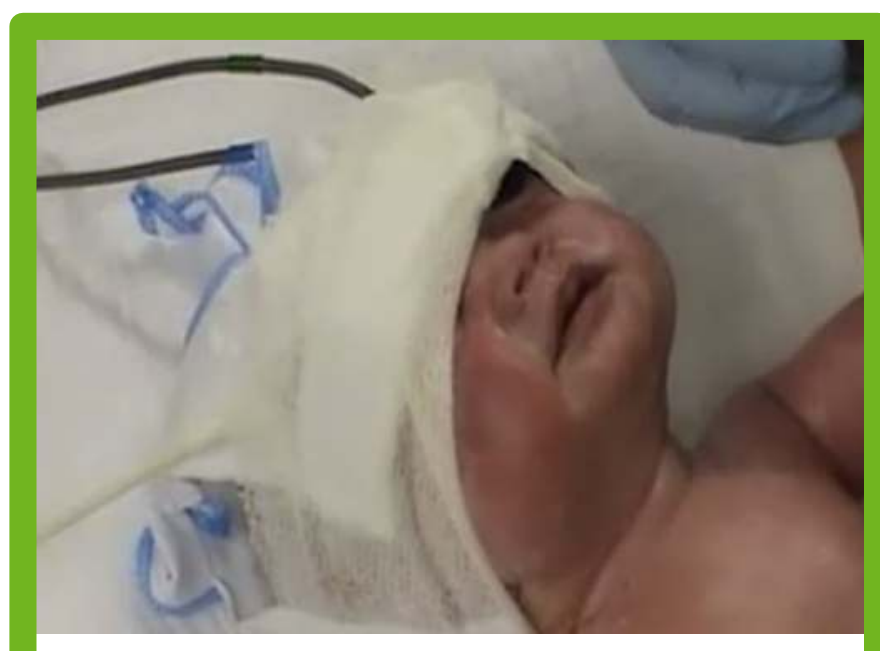

Fig. 1: NIRS transducer attached on the right forehead

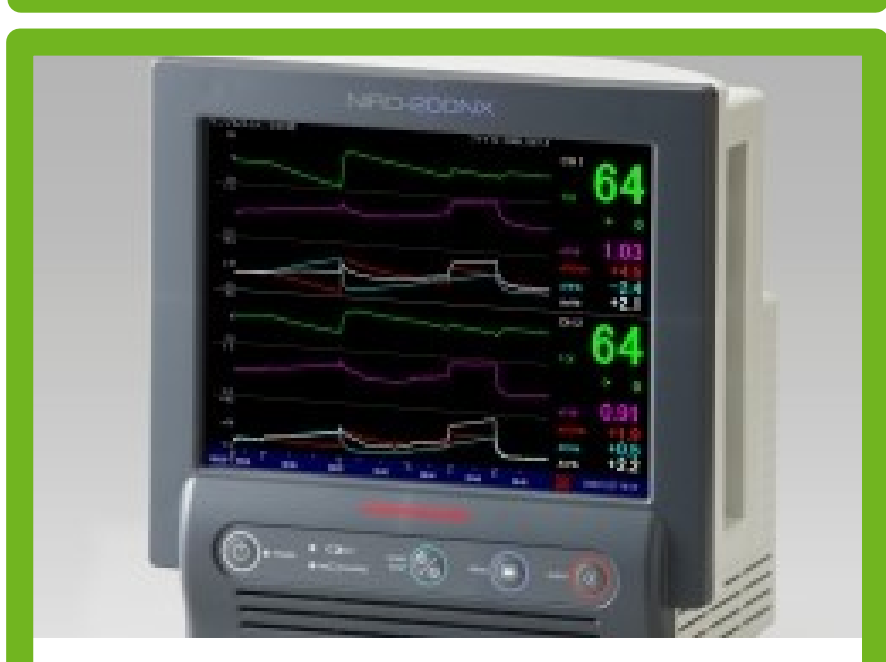

Fig. 3: NIRO-200NX Monitor (Hamamatsu; Japan)

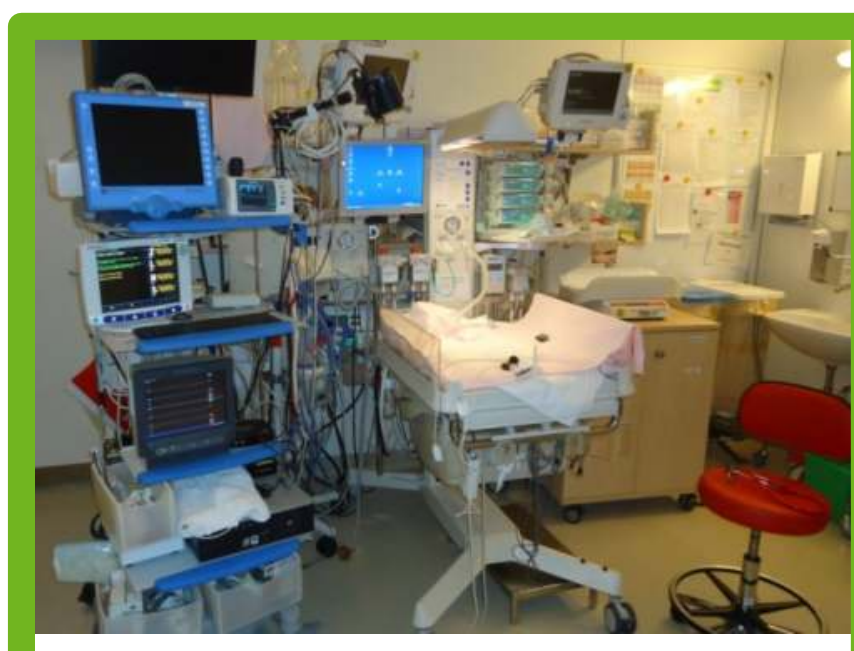

Fig. 2: Research Unit for Cerebral Development and Oximetry

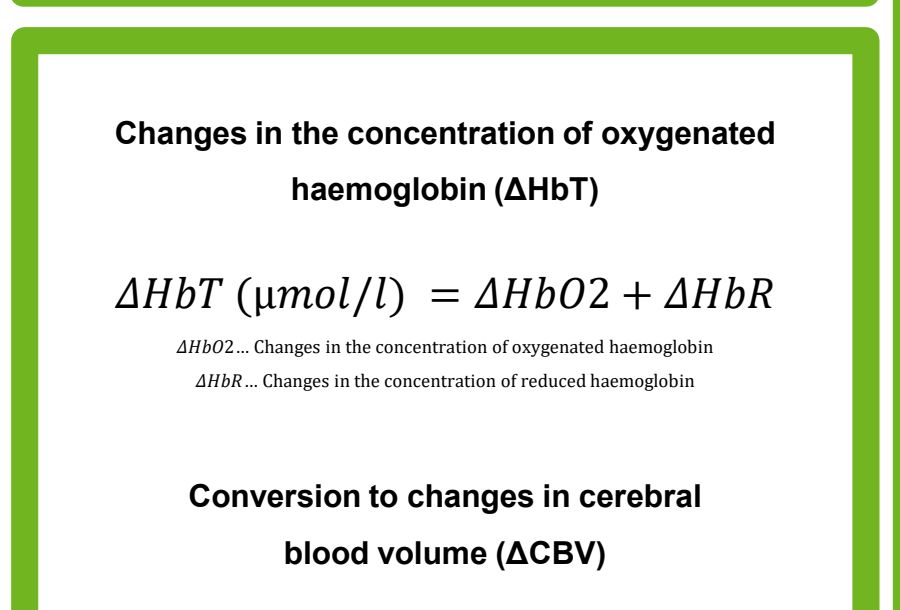

$\triangle C B V(\mathrm{ml} / 100 \mathrm{~g}$ brain $)=\Delta H b T * \frac{0.89}{H b}$

(n)

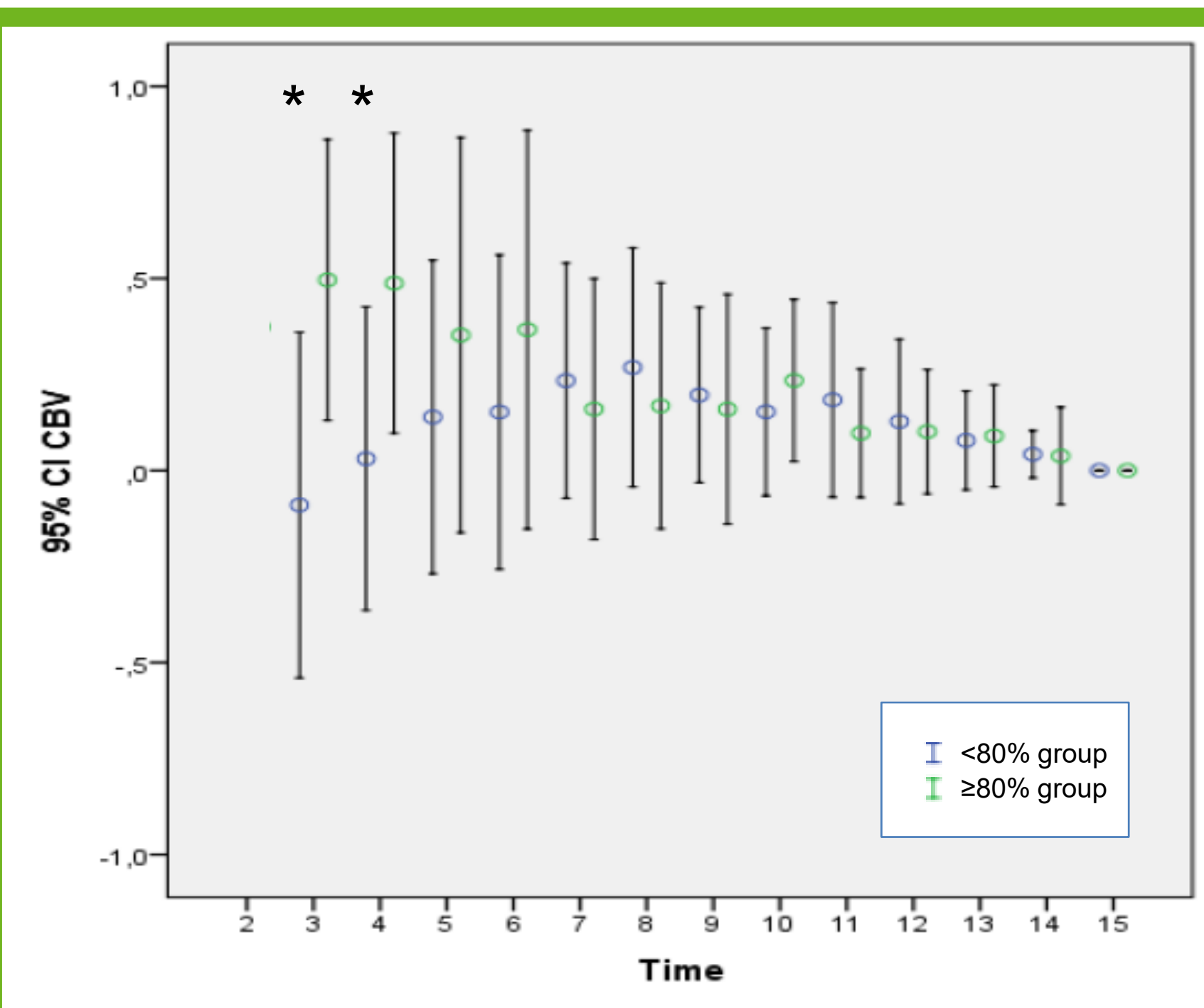

Fig. 4: Changes in cerebral blood volume (CBV) in " $\geq 80 \%$ group" versus " $<80 \%$ group". * $p<0.05$; Data are means and $95 \% \mathrm{Cl}$.

\section{RESULTS:}

Fifty-two preterm neonates were included. 25 infants (48\%) were allocated to the " $\geq 80 \%$ group" and 27 infants (52\%) to the "<80\% group". In " $\geq 80 \%$ group" a decrease in CBV was observed, whereas CBV remained unchanged in "<80\% group". We found significant group differences for $\triangle \mathrm{CBV}$ at minute 3 and 4 (compared to the reference values at minute 15 of age).

CONCLUSION: Preterm infants with respiratory support during delivery room stabilization, reaching the $\mathrm{SpO}_{2}$ target of $80 \%$ at 5 minutes after birth, showed a decrease in CBV. In contrast, CBV remained unchanged in the "<80\% group", which seems to be pathologically. 